\title{
Proceedings of the Fourth Meeting of the EURO Working Group on Operational Research (OR) in Agriculture and Forest Management (EWG-ORAFM)
}

\author{
EDITED BY \\ D. L. SANDARS ${ }^{1 *}$ AND L. M. PLÀं ${ }^{2}$ \\ ${ }^{1}$ Natural Resources Management Centre, Cranfield University, Cranfield, Bedfordshire MK43 OAL, UK \\ ${ }^{2}$ Department of Mathematics, University of Lleida, 73 Jaume II, 25001 Lleida, Spain
}

This working group, which is concerned with operational research methods and applications to agricultural science in its broad meaning (i.e. including Forest Management and Fisheries), was formed in 2003 within the European Association of Operational Research Societies (EURO). The first meeting of the group was held at the former Silsoe Research Institute in 2004. The group holds regular meetings in Europe at approximately yearly intervals, usually within the EURO Conferences. The next meeting will be held at the EURO XXIII conference in Bonn in 2009 followed by the EURO XXIV conference in Lisbon in 2010.

The fourth meeting of the working group was a joint meeting with the British Operational Research Society's special interest group on Agriculture and Natural Resources. It was chaired by D. L. Sandars of Cranfield University and Dr L. M. Plà of the University of Lleida and organized as a stream within the OR50 Conference, and was held at the University of York from 9 to 11 September 2008 where the following papers were read.

\footnotetext{
* To whom all correspondence should be addressed. Email: daniel.sandars@cranfield.ac.uk
} 


\section{ABSTRACTS OF COMMUNICATIONS}

\section{KEYNOTE - A review of the practice and achieve- ments from 50 years of applying $O R$ to agricultural systems in Britain. E. AUDSLEY AND D. L. SANDARS. Natural Resources Management Cen- tre, Cranfield University, Cranfield, Bedfordshire MK43 OAL, UK}

The current paper will survey how things have changed over nearly 50 years of OR applied to agriculture. The first 'OR group' was set up at the National Institute of Agricultural Engineering by Dan Boyce in 1969 and is now at Cranfield University. The current paper will examine how, and what, factors have influenced the type of work and the methods used. What applications have stood the test of time and what are just distant memories in paper publications?

Agricultural OR has moved on from its early beginnings in agriculture in applying OR techniques with simple analyses, to using and creating complex computer models. This follows the growth of computing power and associated techniques. The early network analysis of work-study times of unit operations to identify best procedures to harvest vegetables has disappeared. Dynamic programming and probability methods, which are really only understood by specialists, never quite make it from theory to application, being closest with weeds and modern computers. However, linear program models of farms, while still not applied to actual farms, have found continuing use in combination with GIS databases as part of policy advice (Audsley et al. 2006a), although often driven by economists and with continuing research into what the objective function should be. Rather than techniques, holistic systems modelling for decisions, such as environmental LCA (Williams et al. 2006) and optimizing fungicide decisions (Audsley et al. 2006 b), have become the important OR contributions to agriculture. Although OR might be described as alive, it clearly needs to identify itself and its specific contribution to analysing decisions, to set it apart from the 'anyone can simulate and optimize using a computer'. The distinctive OR skill of holistic systems modelling of combinations of processes at the decision maker level is as important as the ability to use techniques.

Audsley, E., Pearn, K. R., Simota, C., Cojocaru, G., Koutsidou, E., Rounsevell, M. D. A., Trnka, M. \& Alexandrov, V. (2006a). What can scenario modelling tell us about future European scale land use, and what not? Environmental Science \& Policy 9, 148-162.
Audsley, E., Milne, A. E. \& Paveley, N. (2006 b). A foliar disease model for use in wheat disease management decision support systems. Annals of Applied Biology 147, 161-172.

Williams, A. G., Audsley, E. \& Sandars, D. L. (2006). Final report to Defra on project IS0205: Determining the environmental burdens and resource use in the production of agricultural and horticultural commodities. London: Department for Environment, Food and Rural Affairs (Defra).

Five objects of modelling. H. MÜLLER-MERBACH. Informatik und Operations Research, Technische Universitat Kaiserslautern, Germany

Most projects of OR analysis include mathematical models of reality. The current paper reviews the different skills of modelling that are required, depending on the kind of object to be modelled. Five kinds of objects (i.e. five kinds of reality) are to be distinguished (Müller-Merbach 1986; Müller-Merbach 2007):

(i) Man-made structures (such as laws, e.g. tax laws; bill-of-material data; technical designs) require familiarity with the content of the corresponding documents: re-modelling. The reality is already structured, such as in text documents, in tables of data, in technical drawings, etc.

(ii) Man-discovered structures (from natural and engineering sciences) require an understanding of the particular natural 'laws': per-modelling. Many of such natural 'laws' are documented in mathematical terms and have to be adapted to the notation and structure of the model type under construction.

(iii) Empirical findings (such as statistical data, measurement results and observational data), i.e. data without a mathematics-based theory require mathematical creativity: fore-modelling. These data have to be transformed such that they fit with the structure of the model type under construction.

(iv) Man-discovered conjectures (such as hypotheses from the liberal arts and the social sciences) require familiarity with that part of scientific endeavour that include the behaviour of humans: trans-modelling. Due to the limited reliability of the behavioural data, it might become necessary to include some probability or fuzzy set features.

(v) Personal and collective goals (such as objectives for optimization) correspond with the decision 
makers' preferences: pre-modelling. The collective goals respond to the individual goals of the decisions makers (and of others); this variety cannot fully be covered by MCDM features.

The five kinds of objects (i.e. reality) will be presented as a horseshoe: upper level (i and v) for human decisions, middle level (ii and iv) for human discoveries, lower level (iii) for empirical findings, left arm (i and ii) for hard knowledge and right arm (iv and v) for vague knowledge. Sir Charles Popper (1902-94) emphasized the difference: 'Physical laws ... are valid anywhere and always', whereas: 'Sociological laws ... differ in different places and periods' (Popper 1959). Many models refer to more than one kind of object. The particular skills required for the modelling of the five kinds of objects will be discussed.

Müller-Merbach, H. (1986). Letters from the IFORS President. European Journal of Operational Research 25, 423-447.

Müller-Merbach, H. (2007). A system of five object types of ' $a$ posteriori' knowledge. Knowledge Management Research \& Practice 5, 151-153.

Popper, K. (1959). The Logic of Scientific Discovery (translated from: Logik der Forschung). Hutchinson, London. 480 pp. (Revised 1980).

Tabu-search-based scheduling of log trucks. P. HIRSCH AND M. GRONALT. Institute of Production and Logistics, University of Natural Resources and Applied Life Sciences, Feistmantelstrasse 4, A 1180 Wien, Austria

In Central Europe, transportation accounts for an estimated 0.30 of the total costs of round timber. Hence, it is necessary to apply some new sophisticated planning concepts for round timber transport. It starts with the solution of the Transportation Problem (TPP) to optimize the flow of round timber from wood storage locations to industrial sites for a medium-term planning horizon. In order to guarantee that the transported quantities are evenly distributed among the single days of the planning horizon with respect to the workload of the carriers and industrial sites, the Timber Transport Order Smoothing Problem (TTOSP) is solved. The daily routing decisions for log trucks are described by the Timber Transport Vehicle Routing Problem (TTVRP). The TTVRP is characterized as follows: a fleet of heterogeneous log trucks, which are situated at the respective homes of the truck drivers, has to fulfil a number of transports of round timber between different wood storage locations and industrial sites. All transports are carried out as full truckloads. Since the full truck movements are predetermined, the objective is to minimize the overall distance of empty truck movements. In addition to the standard Vehicle
Routing Problem (VRP), one must consider weight constraints on the network, multi-depots and time windows at the depots and industrial sites. Four Tabu Search (TS), a mathematical optimization method, strategies were developed and tested for the TTVRP, which differ with respect to the size of the considered neighbourhood of a solution. The so-called Tabu Search with alternating strategy (TSAS) seems to be a promising method to overcome the high computing times caused by an extensive neighbourhood search. In this method, after a number of iteration steps within a restricted neighbourhood, an iteration step with a full neighbourhood search is triggered. The TSAS is implemented with fixed and dynamic parameter settings. Compared with the Standard TS, which considers the whole neighbourhood of a solution in each iteration step, TSAS is much faster and offers a good solution quality. Comprehensive numerical studies with real-life-sized data compare the different TS strategies with respect to solution quality and computing time. The results show that TSAS with fixed parameter settings needs only between $0 \cdot 25$ and 0.55 of the computing time of TS (depending on these settings); the dynamic TSAS needs between $0 \cdot 40$ and 0.50 of the computing time of TS (depending on the solution path). The best-found solution values of TS and TSAS lie closely together for the considered 40 test cases. The dynamic TSAS performs best with respect to the number of best-found solutions. Standard Solver Software is used to generate lower bounds for the solution quality as a benchmark for the heuristics. These lower bounds may violate some constraints of the TTVRP and are obtained after 86 $400 \mathrm{~s}$ ( $24 \mathrm{~h})$ computing time of Standard Solver Software. The deviations of the heuristically obtained best-found solutions after a computing time of $1560 \mathrm{~s}$ from these lower bounds are between 0.0016 and $0 \cdot 0513$. For a detailed description of the used methods and the TTVRP please refer to Gronalt and Hirsch (2007); the presented results show that the TS methods are capable of solving TTVRPs with good solution quality in reasonable computing times.

Gronalt, M. \& Hirsch, P. (2007). Log-truck scheduling with a Tabu Search strategy. In Metaheuristics - Progress in Complex Systems Optimization (Eds K. Doerner, M. Gendreau, P. Greistorfer, W. Gutjahr, R. Hartl \& M. Reimann), pp. 65-88. New York, USA: Springer.

Delivering products in an agribusiness company: an application case. J. FAULIN ${ }^{1}$, E. DE PAZ ${ }^{1}$, F. LERA $^{2}$ AND J. M. PINTOR ${ }^{3}$. ${ }^{1}$ Department of Statistics and Operations Research, ${ }^{2}$ Department of Economics, ${ }^{3}$ Department of Mechanical Engineering, Public University of Navarre, 31006 Pamplona, Navarre, Spain. 
The current paper describes one of the most important logistic problems of a characteristic group of fruit and vegetable companies situated in Southern Navarre (Spain). Usually, these companies produce frozen vegetables. The main products are the following: peas, beans, cauliflowers, spinach, potatoes, carrots, Brussels sprouts, broccoli, peppers (red, green, sliced, etc.), sweetcorn, Russian salad, oriental salad, American salad, vegetables for soup and vegetables for paella. This wide variety of products requires fresh produce, the raw materials, to be delivered throughout the year. However, the most important crops are peas, beans and peppers. Typically, these companies are the suppliers of large chains of supermarkets in Spain, such as Eroski, Mercadona or Carrefour. Another similar example can be studied in the Gómez \& Salazar's (1991) reference.

Thus, good planning of the pick up and delivery of the aforementioned products is needed. A concrete procedure using the Vehicle Routing Problem model (Toth \& Vigo 2002) was implemented in the current paper. The vehicle routing problems were analysed using heuristic and exact methods. Here, the possibilities of linear programming were studied as a tool for solving problems of distribution. Various transportation problems are considered, making special reference to linear programming models that solve problems of commodity distribution with constraints.

Therefore, the current paper describes the implementation of the MIXALG (MIXed ALGorithm) procedure to the vehicle routing management problem of such agribusiness companies (Faulin $2003 a, b$ ). Furthermore, logistic and transportation activities are analysed in the real managerial world. MIXALG uses some subroutines (heuristic and exact) in order to optimize (minimize) the supply transportation costs and the distribution expenses of the company. Moreover, an important constraint is the supply of raw materials and the delivery of final products at their destinations on time and in the quantity and quality needed.

The results showed not only a reduction of between 8.13 and $18.77 \%$, depending on the algorithm used, in transport and distribution costs but also broadened the scope of the factors that influence decisionmaking. The main advantage of the current model is its flexibility because it can be applied, in a general form, to any firm that is trying to optimize the costs of its own transport system and to employ efficiently its drivers and vehicles. Finally, the outcomes of a new delivery policy in an agribusiness company are presented.

FAulin, J. (2003a). Combining linear programming and heuristics to solve a transportation problem for a canning company in Spain. International Journal of Logistics Research and Applications 6, 17-27.

FAulin, J. (2003b). Applying MIXALG procedure in a routing problem to optimize food product delivery.
Omega-The International Journal of Management Science 31, 387-395.

Gomez, A. C. \& Salazar, A. (1991). Volúmenes óptimos de transporte y transformación en el sector remolacheroazucarero español. Investigación Agraria: Economía 6, 95-107.

Tотн, P. \& Vigo, D. (2002). The Vehicle Routing Problem. Philadelphia, USA: SIAM Monographs on Discrete Mathematics and Applications.

The terminal location problem in a cooperative forest fuel supply network. P. RAUCH. Universität für Bodenkultur (BOKU-University of Natural Resources and Applied Life Sciences), Wien, Austria

In the current paper, the design of a forest fuel network is considered, which aims at minimizing the overall supply cost. The network consists of direct supplies from the forest to a total of 28 combined heat and power (CHP) plants and supply lines by using different terminal types. A Mixed Integer Linear Programme (MILP) model is solved to find an optimal spatial arrangement of terminals by considering different terminal types with respect to their chipping technology and the chipping volume processed. The solution of the MILP models provides a design of the optimal procurement system for the whole study region. The optimal solution requires 19 terminals out of the 38 suggested.

Different scenarios, including changes in transportation cost and inland energy wood utilization rate, are used to test sensitivity of the network design. Simulation of transportation cost changes shows that the optimal network design is stable within an increase of $20-50 \%$ as well as between 70 and $110 \%$. Solutions of the other increased rates show that the optimal number of terminals is decreased when the transport cost rises and when inland mobilization rate increases.

\section{Predicting farmer decision behaviour, taking a plan- ning model beyond profit maximization. D. L. SANDARS AND E. AUDSLEY. Natural Resources Management Centre, Cranfield University, Cran- field, Bedfordshire MK43 OAL, UK}

Stakeholders, such as policy makers, wish to know ex ante or before the event what the consequences of change, such as new policies, technologies, etc., will be. The farmers will strive to optimize their actions given that change, but often in ways that are largely unwelcome and were unexpected at the time. The law of unintended consequences re-occurs.

Profit-maximizing whole-farm linear-programming models, such as the Silsoe Whole Farm Model (SFARMMOD), have been used to analyse this 
situation with some degree of success. The approach is not without its criticism at the level of individual decision makers who seem to have multiple decision objectives (Gasson 1973). However, at an aggregate level profit maximization does describe the collective behaviour of farmers as individual differences average out. Linear programmes are very good at analysing policy based on coercion or exchange, but not policy based on persuasion (e.g. free technical advice or education) (Janssen \& Van Ittersum 2007).

The current paper explores an alternative or modified objective function based on utility or welfare maximization. Utility theory was first put forward by the English Philosopher, Jeremy Bentham. Multi Attribute Utility Theory (MAUT) is made up of numerous goals, such as sufficient income, free time, congenial surroundings, etc. People often exhibit diminishing marginal utility where their last unit of, say, income means less than their first. The optimization problem has now become one of multiple nonlinear objectives. This optimization problem is solved using separable programming.

By combining published sources with farmer interviews six additional components of utility in addition to profit were obtained, which, in total, are represented by 16 measurable attributes. Utility preference curves have been elicited using a curve drawing bisection technique and the trade-off weights using the Swing weight technique (Belton \& Stewart 2002).

Initial results suggest that there are problems with non-independence between attributes, but the profit motive has emerged the stronger objective, as expected. These elicitation methods are typically applied iteratively and the lack of iteration due to practical constraints may be partially to blame for some of the biases. There are major modelling challenges in the representation of the attributes in the linear programme. Validation is also a major issue in that farmers' production decisions are well surveyed, whereas their estate management and conservation decisions are not.

Belton, V. \& Stewart, T. J. (2002). Multiple Criteria Decision Analysis: An Integrated Approach. Dordrecht, The Netherlands: Kluwer.

Gasson, R. (1973). Goals and values of farmers. Journal of Agricultural Economics 24, 521-542.

Janssen, S. \& van Ittersum, M. K. (2007). Assessing farm innovations and responses to policies: a review of bioeconomic farm models. Agricultural Systems 94, 622-636.
Incorporating price variability in a climate change adaptation model. J. M. GIBBONS ${ }^{1}$ AND S. J. RAMSDEN ${ }^{2}$. ${ }^{1}$ School of the Environment and Natural Resources, Bangor University, Bangor, Gwynedd LL57 2UW, UK, ${ }^{2}$ Division of Agricultural and Environmental Sciences, School of Biosciences, University of Nottingham, Sutton Bonington Campus, Loughborough, Leicestershire LE12 5RD, UK

An approach to introducing price instability into a dynamic catchment-level optimization model, comprising 29 representative mixed integer-programming sub-models, is described. The existing model includes simulated weather-induced yield variability, irrigation demand and climate effects up to the 2050s for part of the Nar catchment in the East Anglian region of England. Decision makers within each sub-model go through a plan-making step, where previous years' data (for example, yields) are used to form expectations on what will occur in the next year. The plan-making step results in an optimal farm plan for the expected values; however, the actual outcome will differ from the expected values due to weather variability; therefore, a resolution step is used to determine the actual outcome of the 'optimal' farm plan; for yield, values are obtained from a bootstrap sample of 50 years of simulated yield data. In the existing model, the only data that vary across years are crop yields and irrigation demand for root crops: potatoes and sugar beet. Clearly, agricultural prices are another source of variability. The modelling process was therefore extended to include bootstrap sampling of market price data to generate output variability (yield and price) estimates for winter wheat, winter barley, winter oilseed rape, sunflowers, potatoes and sugar beet. It was assumed that price and yield for the catchment were independent; however, the positive co-variability of different crop prices was maintained. Other than these changes, the model was identical to that reported in Gibbons \& Ramsden (2008); here, the model was used to generate results for the Nar catchment, under climate and weather effects for the 2020s and 2050s. These results were compared with those from the 'with price variability' model, emphasizing differences in irrigation demand, investment in irrigation capacity and root crop areas. The paper concludes with a discussion of the limitations of the approach and the trade-offs associated with adding to model complexity in biological and socioeconomic systems.

Gibbons, J. M. \& Ramsden, S. J. (2008). Integrated modelling of farm adaptation to climate change in East Anglia, UK: scaling and farmer decision making. Agriculture, Ecosystems and Environment 127, 126-134. 
Using a discrete stochastic programming model to estimate climate change effects on crop/livestock systems in semi-arid areas. $M$. BENDAOUD AND M. RIVINGTON. Macaulay Institute, Craigiebuckler, Aberdeen AB15 8QH, UK

Crop productivity in arid and semi-arid areas is subject to high variability, mainly determined by the rainfall distribution. In the mixed livestock/cropping systems, an animal's productivity and profitability is greatly dependent on crop and pasture yields.

A mathematical programming bio-economic farm model has been developed to simulate different scenarios of climate change and policy reforms. The model was parameterized using mainly a long-term trial run in Aleppo, northwest Syria.

The model includes detailed modules for livestock, nutrition and herd dynamics. The crop module uses an empirical model to link a climatic database to crop yields and pasture growth. The crop and livestock activities are linked through storage consumption or pasture growth and grazing dynamics.

The model is run for a cropping season (1 year) and is dynamic with 12 time periods (months). The decision process is stochastic and permits options allowing generation of strategic and tactical decisions to adjust to the new risk conditions and information.

The risk behaviour model considered is the 'Target MOTAD' approach (Tauer 1983). The specifications of the model are its stochastic structure, the detailed animal biological components and their integration within a coherently structured decisionmaking model.

The model simulates the flexibility of the agriculture of arid lands by adjustments of herd sizes, animal performance and feeding strategies, with a set of 45 strategies and tactics corresponding to 45 discrete stochastic sequences of states of nature defined for three seasons (autumn, winter and spring). This model was used to compare a baseline situation to a scenario of climate change.

TAuer, L. W. (1983). Target MOTAD. American Journal of Agricultural Economics 65, 605-610.

How to choose: prioritizing the removal of fish passage barriers. J. O'HANLEY ${ }^{1}$ AND D. TOMBERLIN ${ }^{2}$. ${ }^{1}$ Kent Business School, University of Kent, Canterbury, Kent CT2 7PE, UK, ${ }^{2}$ National Marine Fisheries Service, Santa Cruz, CA, USA

The presence of small artificial barriers that hinder the upstream migration of fish is a critical and challenging problem in riparian habitat restoration planning. Far and away the most common method for prioritizing barrier removal and repair decisions is scoring and ranking. Although simple to use and apply, scoring-and-ranking procedures fail to account for the spatial arrangement of barriers. Thus, they can be highly inefficient in terms of producing upstream habitat gains. This is very clearly demonstrated using both an artificial network and a real-life dataset of barrier culverts located in the state of Washington, USA. To help address this shortcoming, an integer programming formulation is presented along with exact and heuristic solution methods in order to find optimal or near-optimal solutions to the problem of passage barrier removal and repair. As a further problem extension, a simple bio-economic model of fish population growth and harvesting is also presented and analysed.

Emergy analysis of Scottish cropping system. C. F. E. TOPP $^{1}$, M. DEBELJAK ${ }^{2}$ AND G. SQUIRE ${ }^{3} .{ }^{1}$ Land Economy and Environment Department, $S A C$, West Mains Road, Edinburgh EH9 3JG, UK, ${ }^{2}$ Department of Knowledge and Technologies, Jozef Stefan Institute, Jamova 39, Ljubljana SI-1000, Slovenia, ${ }^{3}$ Scottish Crop Research Institute, Invergowrie, Dundee DD2 5DA, UK

Arable/grasslands have to be multi-functional; hence, they need to be managed to preserve their own integrity, ensure food security, satisfy social preferences for biodiversity, scenery and access, provide a living for farmers, respond to economic realities, and take on new biotechnology and global shifts in climate. As an initial step to assess the health and sustainability of arable/grassland systems, emergy analysis is being conducted. Emergy synthesis is based on open system thermodynamics and is measured in solar emergy joules. It was developed to evaluate ecosystem processes and their properties. One of its major advantages is the ability to evaluate systems that are driven by multiple forms of energy, and hence ecological, economic and social aspects of the farming system are included in the analysis, and compared on the basis of a common currency. It is based on the maximum empower principle, which is regarded as a general criterion for judging the impacts of human activities on the planet. The basis for this concept is that as energy is transformed from one component to another, the total quantity of energy decreases, but the quality increases. The transformity of a product, which is used to convert energy to emergy, is the ratio of the energy previously used up to make a product divided by the energy remaining in the product. In order to apply emergy analysis to a system, it is necessary to have knowledge about and to understand its internal relationships and to quantify the energy and mass flows entering and leaving the system. Hence, for an agricultural system data are required on solar energy, rainfall, loss of topsoil, fuel use, seeds, fertilizer and pesticide inputs, labour, 
mechanical inputs and production from the farm. The viability of the farming system will be assessed by the following four major indices:

- How much local renewable resources have been activated by the particular crop field?

- How much non-renewable resources have been activated within and outside the particular crop field?

- What is the general efficiency of energy use by particular crop field?

- What is the sustainability index of particular crop field?

\section{A systems modelling approach to Life Cycle Inventories of agricultural and horticultural pro- duction. E. AUDSLEY AND A. G. WILLIAMS. Natural Resources Management Centre, Cranfield University, Cranfield, Bedfordshire MK43 OAL, UK}

To support policy decision-making, it is necessary to know how environmental impacts are changed by alternative methods of producing primary agricultural commodities, such as wheat, potatoes, chicken, beef, milk and lamb. Should one reduce the input of fertilizers, pesticides, and cultivation energy? Should one feed cows more concentrates for higher yields per cow to reduce the maintenance feed per litre of milk? Is organic farming better? A system-model-based environmental Life Cycle Assessment (LCA) is used to calculate the burdens of producing food commodities (see www.agrilca.org; Williams et al. 2006). An essential aspect is that the functional unit is a tonne of the commodity not an area of land.

Models of the systems and process ensure that when changes are made, they are properly accounted for and components that are linked to them also change. This ensures that short-termism is not practiced, because, for example, soil provides a large nutrient buffer that could be plundered for several years before yields fall. This is clear when comparing typical short-term crop yield $v$. fertilizer response curves with those from the long-term experiments.

Livestock farming, particularly sheep, has integrated systems of cross-breeding to build hybrid vigour. Thus, hill farmers produce ewe lambs for upland farmers who produce cross-bred ewes for lowland farmers who produce the majority of the lambs eaten. Models define these industry structures and how they must change if, for example, lowland or hill farming is not sustainable. Feed models link the outputs to nutritional demand, fertility, productivity and manure production. A manure model estimates the long-term release of nutrients, which displaces the need for fertility or increases yields, and the emissions to the air.

This modelling provides a highly interactive framework for the analysis. The results of studying proposals for improving environmental burdens of food production are instructive. The key variable for reducing agricultural burdens is nutrient utilization efficiency and not, for example, how many eggs a hen lays per year. Increasing milk yield has no effect on energy needed per litre of milk; reducing fertilizer has only a small effect of energy per tonne of grain. Although organic farming causes some reduction in energy required, it also increases leaching of nitrate to water and requires considerably more land.

Williams, A. G., Audsley, E. \& Sandars, D. L. (2006). Final Report to Defra on Project IS0205: Determining the Environmental Burdens and Resource Use in the Production of Agricultural and Horticultural Commodities. London, UK: Department for Environment, Food and Rural Affairs (Defra).

The use of time series modelling to assess the impact of media campaigns on cases of food poisoning. D. HOLLAND AND E. PUNTON-LI. Food Standards Agency, UK

The biggest food safety issue currently in the UK is foodborne illness, more commonly known as food poisoning. The symptoms and effects of foodborne disease are unpleasant and in some instances can cause death, with around 500 fatalities a year in the UK.

Since 2002, the Food Standards Agency has run a number of food hygiene media campaigns as part of its strategy to reduce cases of foodborne disease. These campaigns have focused on a range of hygiene messages, such as cross-contamination and cooking food properly.

Although the Agency has good evidence from surveys that public awareness of the issues has increased following these campaigns, there had been no evaluation of the effect on the actual number of cases of foodborne disease. This was due to the difficulty of knowing what the numbers of cases would have been if the campaigns had not taken place.

To evaluate the likely impact on actual cases, time series models were produced for the two most common forms of foodborne disease in the UK - these are Campylobacter and Salmonella. The analysis was based on the number of laboratory reported cases in England and Wales.

Models were produced using two separate techniques, namely Structured Times Series Modelling (Harvey et al. 1997) and Autoregressive Integrated Moving Averages (ARIMA) (Box \& Tiao 1975). Each took into account the underlying trend, seasonality and significant explanatory variables. The results from the two techniques were similar both in terms of the structure and in the values of the predictions. 
The models were then used to forecast the number of cases of foodborne disease from the start of each campaign. Where there was an over-forecast for a number of weeks following the campaign, a campaign variable was added and tested for significance. From this, an overall estimate of the likely reduction in the number of cases of foodborne disease was calculated using ascertainment rates determined by Adak et al. (2002).

As well as estimating the likely impact of campaigns, this approach can also be used to provide insights as to what types of campaigns work and when to run them.

The authors would like to acknowledge Adam Crowe, an MSc student from the London School of Economics, who did much of the analysis.

Adak, G. K., Long, S. M. \& O'Brien, S. J. (2002). Trends in indigenous foodborne disease and deaths, England and Wales: 1992-2000. GUT-An International Journal of Gastroenterology and Hepatology 51, 832-841.

Box, G. E. P. \& TIAO, G. C. (1975). Intervention analysis with applications to economic and environmental problems. Journal of the American Statistical Association $\mathbf{7 0}$, 70-79.

Harvey, A. C., Koopman, S. J. \& Marco, R. (1997). The modelling and seasonal adjustment of weekly observations. Journal of Business and Economic Statistics 15, 354-368.

Optimal replacement policies for dairy cows based on daily yield measurements. L. RELUND-NIELSEN. Department of Genetics and Biotechnology, University of Aarhus, Denmark

In agriculture, Markov decision processes (MDPs) with finite state and action space have often been used to model sequential decision making over time in dairy herds. However, the length of each stage has been at least one month, resulting in the models being rarely used at an operational level in modern herd management systems.

In the current paper, a multi-level hierarchic MDP calculating optimal replacement decisions is developed. The model considers time steps of 1 day and is based on daily milk yield measurements that are available in modern milking systems. A state space model for the daily milk yield is formulated and embedded into the MDP.

Optimization of piglet production with a stochastic dynamic programming model. J. K. NIEMI. Agrifood Research Finland (MTT), Economic Research, Luutnantintie 13, FI-00410 Helsinki, Finland
Sow replacement decisions are among the most important management decisions in piglet production. After each farrowing, Finnish piglet producers replace, on average, some 0.25 of sows with a new gilt, and replacement costs typically incur $0 \cdot 10-0 \cdot 15$ of production cost of a piglet. Improvements in management and genotype of animals can therefore improve the profitability of pig farming. However, the piglet producer faces great uncertainty about future productivity of both current and replacement sows.

The current paper presents a stochastic dynamic programming model for optimizing replacement decisions. Stochastic dynamic programming is well suited to modelling the uncertainty about future productivity because it can take into account that the producer can update management decisions when new information regarding productivity is obtained and thus uncertainty is partially revealed. The state variables provide information on litter size and parity. Transition equations used in the model filter information from the production process and condense it into the state variables, i.e. parity and litter size (Kristensen \& Søllested 2004). The model is applied to an empirical problem where the producer optimizes replacement decisions after committing to one of two genotypes (i.e. production technologies). Technologies differ in productivity so that one produces more piglets than the other, but the difference in litter size is unknown.

The model suggests that uncertainty about litter size affects returns per animal place in two opposite ways. Firstly, when variation in piglet yield over parity is taken into account and replacement decisions are adjusted according to the observed yield, an increase in variation can increase returns per sow place. However, if variation in litter size increases only a little, the impact on returns can be small as the repeatability of litter size between successive parities is quite low. For instance, a $10 \%$ increase in variation in litter size increased return on sow place only by $€ 17$. Secondly, in cases where the option value is not taken into account, an increase in variation can decrease returns per sow place. The option to first learn the benefits of a new technology and only thereafter commit to it is valuable particularly when estimated difference in productivity is smaller than standard deviation of the estimate.

Kristensen, A. R. \& Søllested, T. A. (2004). A sow replacement model using Bayesian updating in a three-level hierarchic Markov process: II. Optimization model. Livestock Production Science 87, 25-36.

Capacity building in the Kenya dairy industry. Z. KIRUTHU ${ }^{1}$ AND W. IRAKI ${ }^{2}$. ${ }^{1}$ University of Ghent, Belgium, ${ }^{2}$ University of Nairobi, School of Business, Kenya 
Development is borne out of continuous improvement, yet Kenya's agricultural sector has been slow in embracing new practices or improving existing ones. Extension services that used to be the vanguard of continuous improvement in Kenya's agricultural sector have dwindled since the liberalization of the economy in the 1990s.

The current topic is motivated by the realities of post-economic liberalization, culminating in the realization that if Kenya has to develop faster, focus on agricultural sector improvement, where most of its rural poor derive their livelihood, is of paramount importance. The current paper focuses on the Kenyan dairy industry, specifically how its performance can be enhanced by building the capacity of the primary stakeholders through: good agricultural practices such as record keeping, animal husbandry, healthcare and nutrition and extension services; logistics/supply chain management; good hygienic practices in milk handling and storage; and improved market access. The industry is dominated by small-scale farmers who generally do not employ formal methods for the continuous improvement of knowledge and skills resulting in challenges such as high production and transportation costs, high post-harvest losses (milk spoilage and spillages), quality and safety concerns and limited market access. An informal market, where a larger proportion of the marketed raw milk (Kenya Dairy Board, June 2008) is sold to direct consumers without either preservation or value addition, compared to what is processed, has evolved. This has led to subsistence agriculture, which is not a viable option for eliminating poverty (von Braun \& Kennedy 1994). The farmers and their cooperative have no existing models to plan; they use rules of thumb and 'negotiations'. In order to address the farmer's plight Operations Research (OR) models, such as transportation, inventory and network analysis, used in other sectors such as manufacturing and engineering to drive their continuous improvement, will be used. The main question is how to build and sustain the capacity of individual farmers, farmer groups and cooperatives subsequently inculcating a self-propelled continuous improvement culture and enhancing performance and sustainable development. By interviewing farmers, and observing them in practice, useful lessons on how to build and sustain capacity in the dairy industry will be learnt.

Von Braun, J. \& Kennedy, E. (1994) Conclusions for Agricultural Commercialization Policy. In Agricultural Commercialization, Economic Development and Nutrition. (Eds J. Von Braun \& E. Kennedy) pp. 365-376. Baltimore, USA: The John Hopkins University Press for the International Food Policy Research Institute.
A branch-and-price algorithm for harvest scheduling subject to maximum area restrictions. I. MAR-

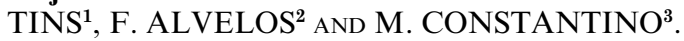
${ }^{1}$ Instituto Superior de Agronomia, Centro de Investigação Operacional, Portugal, ${ }^{2}$ Universidade do Minho, Centro Algoritmi, Portugal. ${ }^{3}$ Faculdade de Ciências de Lisboa, Centro de Investigação Operacional, Portugal

The current work considers a forest harvestscheduling problem, with restrictions on the maximum clear-cut area, known in the literature as Area Restriction Model (ARM). In this problem, stands are substantially smaller than the maximum clear-cut area, so that harvesting simultaneously two neighbouring stands does not necessarily represent a spatial violation.

Three major integer-programming formulations have been proposed for the ARM. The first formulation has an exponential number of constraints (e.g. Martins et al. 1999; McDill et al. 2002). The second model has an exponential number of variables (e.g. Martins et al. 1999; Goycoolea et al. 2005). The third formulation encompasses a polynomial number of variables and constraints (Constantino et al. 2008). All of these formulations constitute an important step in being able to solve the ARM to optimality. Solving these formulations via branch-and-bound is well suited for real problems of small to medium size but not for larger problems.

Branch-and-price is an appealing technique for integer programming models, where the number of variables is extremely large, as every linear programme in the branch-and-bound tree is solved with a sufficiently meaningful subset of variables. The current work proposes a branch-and-price algorithm for the second model. One building block, the pricing sub-problem, is to find, for each period, a subset $S$ of stands such that the sum of the weights of the stands minus the weights of the cliques intersecting $S$ is maximum and the area of $S$ does not exceed the maximum clear-cut area. The computational complexity of this problem is nondeterministic polynomial-time hard (NP-hard).

Computational results indicate that branch-andprice is able to obtain solutions within 0.001 of the optimum in reasonable time. This conclusion is similar to Vielma et al. (2007), who use the same model but generate all columns a priori. However, the number of columns increases exponentially with the ratio between the maximum clear-cut area and the average area of stands. Nevertheless, the tests presented here indicate that the time to obtain a good solution with the branch and price approach does not depend on that ratio. Finally, it is important to point out that these are preliminary results, so more tests have to be done. 
Constantino, M., Martins, I. \& Borges, J. G. (2008). A new mixed integer programming model for harvest scheduling subject to maximum area restrictions. Operations Research 56, 542-551.

Goycoolea, M., Murray, A. T., Barahona, F., Epstein, R. \& Weintraub, A. (2005). Harvest scheduling subject to maximum area restrictions: exploring exact approaches. Operations Research 53, 490-500.

Martins, I., Constantino, M. \& Borges, J. G. (1999). Forest Management Models with Spatial Structure
Constraints. Working Paper No. 2/1999. Faculdade de Ciências, Lisbon: C.I.O.

McDill, M. E., Rebain, S. A. \& Braze, J. (2002). Harvest scheduling with area-based adjacency constraints. Forest Science 48, 631-642.

Vielma, J. P., Murray, A. T., Ryan, D. M. \& Weintraub, A. (2007). Improving computational capabilities for addressing volume constraints in forest harvest scheduling problems. European Journal of Operational Research 176, 1246-1264. 